$$
\begin{gathered}
B C / 14989-12 \\
D O E / B C / 14989-12
\end{gathered}
$$

APPLICATION OF INTEGRATED RESERVOIR MANAGEMENT

AND RESERVOIR CHARACTERIZATION

TO OPTIMIZE INFILL DRULLING

Cooperative Agreement Number: DE-FC22-94BC14989

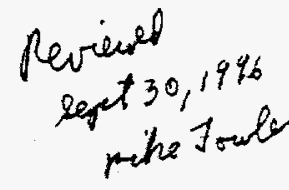

FINA OIL AND CHEMICAL COMPANY

Report Date: September 12, 1996

Award Date: June 13, 1994

Anticipated Completion Dates:

Budget Period I - March 12, 1996

Budget Period II - June 12, 1999

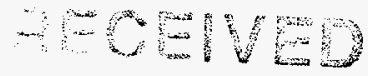

MAR 251997

OSTI

Government Award for Budget Period II: \$7,572,930.00

Program Manager: J.W. Nevans

Principal Investigator: Fina Oil and Chemical Company

Team Members

Center for Economic and Energy Diversification

David K. Davies and Associates

Fina Oil and Chemical Company

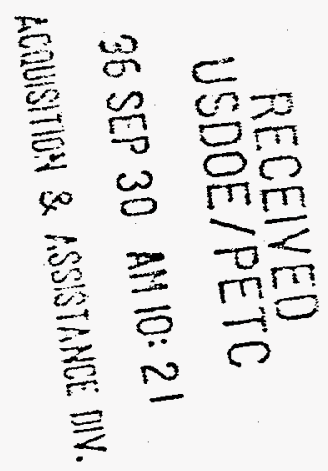

Mobil Exploration and Producing U.S. Inc.

Schlumberger Well Services

Texas A\&M University

The University of Tulsa

Contracting Officer's Representative (COR):

Rhonda Lindsey, DOE Bartlesville

Reporting Period: June 13, 1996 to September 12, 1996 


\section{DECALAMER:}

Portions of this document may be illegible in electronic image produets - Images are: produced from the best available original document. 


\section{DISCLAIMER}

This report was prepared as an account of work sponsored by an agency of the United States Government. Neither the United States Government nor any agency thereof, nor any of their employees, make any warranty, express or implied, or assumes any legal liability or responsibility for the accuracy, completeness, or usefulness of any information, apparatus, product, or process disclosed, or represents that its use would not infringe privately owned rights. Reference herein to any specific commercial product, process, or service by trade name, trademark, manufacturer, or otherwise does not necessarily constitute or imply its endorsement, recommendation, or favoring by the United States Government or any agency thereof. The views and opinions of authors expressed herein do not necessarily state or reflect those of the United States Government or any agency thereof. 
QUARTERLY TECHNICAL PROGRESS REPORT

"APPLICATION OF INTEGRATED RESERVOIR MANAGEMENT AND
RESERVOIR CHARACTERIZATION TO OPTIMIZE INFILL
DRILLING"

INSTRUMENT NO. DE-FC22-94BC14989

NORTH ROBERTSON UNIT DEPARTMENT OF ENERGY CLASS II OIL PROGRAM PROJECT

REPORTING PERIOD: 6/13/96 TO 9/12/96

This Quarterly Progress Report summarizes the technical progress of the project from 6/13/96 TO 9/12/96.

ACTIVTTY II.1 - MANAGEMENT AND ADMINISTRATION

PROJECT MANAGEMENT AND ADMINISTRATION - TASK 1I.1.1

\section{Project Status}

At this time, eighteen (18) 10-acre infill wells have been drilled as part of the Field Demonstration phase of the project. Of the fourteen producing wells drilled to date, twelve are currently on production, and ten are pumped-off and producing at stable rates. Current Unit production is approximately $3,600-3,700 \mathrm{STBO} / \mathrm{D}$, and approximately $850 \mathrm{STBO} / \mathrm{D}$ incremental production has been added to date (Fig. 1). The remaining producing well and four injection wells are currently being completed. A change in the Statement of Work has been approved so that we can drill additional 10-acre infill wells during the next quarter as budget constraints allow.

Production flowlines are laid for each new producing well as they are put on production. Injection lines are being laid for the injection wells as they are completed. All data required for the validation of the Budget Period I Reservoir Characterization, Reservoir Management, and Reservoir Simulation Studies are being acquired and analyzed during the Field Demonstration Period. 


\section{ACTIVITYII.2 - FIELD DEMONSTRATION}

\section{IMPLEMENTATION OF FIELD DEMONSTRATION - TASK II.2.1}

\section{Drilling and Completion}

The drilling phase of the Field Demonstration proceeded smoothly and was completed on schedule. Eleven Phase I wells were drilled between March 15 and July 5, 1996, consisting of nine producing wells and two water injection wells. Ten of the wells were drilled to complete waterflood patterns in the North (Section 329) and South (Section 327) 10-acre infill areas of the Unit. An additional off-pattern well, NRU 3319, was drilled in Section 362 of the Unit in a twenty-acre location that had not previously been drained by existing producers (Fig. 2).

The seven Phase II wells were drilled between July 3 and August 20, 1996. Phase II consisted of five producing wells and two water injection wells. The Phase II locations were chosen during a team member meeting at the end of June, and location selection was based on data acquired during Phase I. Phase II drilling consisted of completing waterflood patterns to the West of the Phase I wells in Section 329 and Section 327 of the Unit. An additional off-pattern well, NRU 3604 , was drilled in a 10-acre location in the southwest corner of Section 324, in an area of the Unit in which reservoir flow simulation predicted extremely high recovery potential (Fig. 2). The off-pattern wells drilled during the Field Demonstration will be given additional injection support by converting two to three offset producers to injection wells in the near future.

\section{Core Analysis}

We have taken 2,730 feet of core in four wells as part of an intensive effort to collect needed rock data. The data will be used to help quantify the extent of small scale vertical and lateral heterogeneity, refine the depositional model, improve our understanding of the relationship between porosity and permeability, and help us choose additional 10-acre infill drilling locations within the NRU Clearfork Formation.

We attempted to cut cores continuously through the entire Clearfork section. Parts of the section were not cored due to significant mechanical difficulties caused by very long core times--often greater than 200 minutes per foot. This continuous core gives us the ability to make foot by foot comparisons of reservoir quality, rock type, and depositional environment, which ultimately will help us correctly model fluid movement within the reservoir.

Fina geologists were very careful to capture high quality data from the core by following these rigorous procedures:

1) The core was pulled from the barrel and loaded into 6 inch PVC tubes that were immediately filled with degassed lease crude and then sealed. 
2) The core was carefully laid out at the lab ensuring that care was taken to properly mark depths and lost core intervals.

3) 1 inch by 1 inch plugs were taken every foot, exactly 0.1 feet below the foot mark. These plugs were measured by Core Labs for helium porosity, air permeability, and grain density. All of this data was loaded into a geological-petrophysical computer database program, then depth shifted.

4) 'Whole' core analyses were taken at promising looking reservoir intervals. Data will be loaded into the computer database and depth corrected.

5) 1.5 inch by 3 inch Special Core Analysis (SCAL) plugs were taken in all potential reservoir intervals and in all rock types. These plugs were stored in sealed containers filled with degassed lease crude to preserve the native state of the rock characteristics and fluid content.

6) Fina slabbed all the core at their own facility to maintain high quality assurance.

7) Depositional environment and rock type using Dunham's classification were described from the slabbed core.

8) Permeabilities and porosities were measured from a selected $150 \mathrm{ft}$ of the NRU 3533 core using Core Labs PDK-100 mini-permeameter machine. Three permeability traces, 0.1 inches apart, were recorded. Measurements were taken vertically each 0.1 inch. Acoustic-measured porosities were also recorded, using one trace down the center of the core slab, every 0.1 inch.

\section{FIELD OPERATIONS AND SURVEILLANCE - TASK II.2.2}

\section{Operations}

All new wells are being operated in accordance with Fina Oil \& Chemical's normal operating procedures.

\section{Production Tests}

All new wells are placed on daily test for a period of two to three weeks, or until their rates have stabilized. 24-hour production tests will be performed two to three times a month on each well (new and existing) in accordance with Fina's normal operating procedures.

\section{Interval Testing and Pre-Production}

The two injection wells in Section 329 will be 'pre-produced' for a three or four week period (as per the Texas RRC), prior to placing them on injection, in order to obtain the early 'flush' production in the near-well area that is a producing characteristic of the reservoir. In addition, we will conduct near-wellbore wettability tests to try to optimize both injection and production in all wells. After the well is placed on production, we will attempt to water-wet the near-wellbore region to increase production efficiency. Making the rock water-wet in the near-wellbore region 
will mean that the water will be coating the rock surfaces and that the oil will be in the center of the pore space. When the well is placed on injection, we will attempt to oil-wet the nearwellbore region so that oil is coating the rock grains and water is in the center of the pore space, thereby increasing injection efficiency. Previous special core data has shown that the Clearfork interval possesses either oil-wetting tendencies or mixed wettability characteristics. We hope to verify or disprove this both in the field and in the lab during our new special core studies.

Interval testing was performed on the Lower Clearfork zone on two wells, and on the Middle Clearfork zone on two wells, in order to determine the relative contribution of each completed interval to production. In addition to interval producing rates, pressure drawdown data was recorded as each well's producing fluid level was pumped down, and pressure transient analyses were performed to provide information concerning the production efficiency of each zonal completion. Additional testing will be conducted on two wells in the near future. The results of these tests are summarized in the Reservoir Management section of the report.

\section{Well Stimulation}

As a result of the data acquisition process (core and logs) during the Field Demonstration phase of the project we have found that we could identify discrete intervals within the Glorieta/Clearfork section that contribute most to production. These are intervals of relatively high permeability and porosity reservoir, which are separated by larger intervals of lower permeability and porosity rock that act as source beds for the higher quality reservoir rock. These intervals include:

Lower Clearfork: MF4 and MF5 zones $\quad( \pm 7,000$ to $7,200 \mathrm{ft})$

Middle Clearfork: MF1A, MF2, and MF3 zones $( \pm 6,350$ to $6,500 \mathrm{ft}$, and $\pm 6,750$ to $6,900 \mathrm{ft}$ )

Upper Clearfork: CF4 Zone $\quad( \pm 6,150$ to $6,250 \mathrm{ft})$

We have utilized three-stage completion designs to keep the treated intervals between 100 and $250 \mathrm{ft}$. We have performed both $\mathrm{CO}_{2}$ foam fracs and conventional cross-linked borate fracs using a new premium frac fluid on an equal number of new wells, with outstanding results for both designs. The advantages of each type of frac design are listed below:

$\mathrm{CO}_{2}$ Foam Fracs: exceptionally clean frac fluid

increased relative oil permeability

created solution gas drive reduces cleanup requirements

formation of carbonic acid for near-well stimulation

reduction in interfacial tension helps remove water blocks

Cross-linked Borate: exceptionally clean frac fluid

low fluid loss without formation-damaging additives

excellent proppant-carrying capacity 
polymer-specific enzyme breaker aids in post-frac cleanup $90 \%$ of original fracture conductivity retained

Pre-frac cleanup acid jobs have been performed to remove near-well damage using between 1000 and 3000 gallons of $15 \%$ acid. Most intervals have been perforated for limited-entry fracturing ( $>2 \mathrm{bbl}$ per perforation), with average injection rates between 30 and 40 barrels per minute, depending on the size of the interval. The size of the frac jobs has ranged from 35,000 gallons of fluid and 55,000 lbs of 16/30 sand to 70,000 gallons of fluid and 150,000 lbs of 20/40 sand. Resin-coated sand has been 'tailed-in' for all frac jobs to reduce sand flowback during production. The conventional fracs have been flowed back immediately at 1 barrel per minute to induce fracture closure, while the foam fracs have been shut-in 2-5 days after stimulation to allow the $\mathrm{CO}_{2}$ to soak into formation.

All jobs have been radioactively traced to estimate vertical fracture propagation. Using this information, we have been successful in avoiding fracturing down into an underlying water zone in the Lower Clearfork, and we have been able to avoid any fracture communication between stages. All hydraulic fracture jobs were designed to yield fracture half-lengths of approximately $150 \mathrm{ft}$. Post-frac pressure transient tests performed over specific completion intervals indicate that we are obtaining fracture half-lengths between 80 and $120 \mathrm{ft}$ with average radial flow skin factors of approximately -5.0 .

\section{Oil Fingerprinting}

Surface oil samples have been collected from each interval completion on all new wells for oil fingerprinting analysis. The samples have been sent to D.B. Robinson Fluid Properties, Inc. in Houston, Texas for compositional analysis. The oil samples are processed using centrifuge and filtration processes to remove suspended water and other organic material to obtain the best representative sample from each producing interval.

As with most shallow-shelf carbonate reservoirs in the Permian Basin, we are dealing with a large productive interval, in which small individual zones contribute most of the production. Traditional methods for identifying zonal contributions do not work well in this Glorieta/Clearfork interval because the wells do not flow naturally. As an example, in order to record a production log survey, flow must be induced through artificial means that are not representative of the 'normal' reservoir flow mechanisms.

We will work with D.B. Robinson to determine if this cost-effective technology is a viable method for calculating each producing interval's contribution to total production. Information obtained from these tests, and from the interval pressure transient tests we are currently performing, will allow for better targeting of productive intervals in future wells, a reduction in completion costs, and a more efficient completion. We will continue to report on the progress and results of this program during the next few quarters. 


\title{
TDT Logging
}

A second series of Thermal Decay Time (TDT) logs will be recorded beginning in the fourth quarter of 1996 in the same wells in which data was collected during Budget Period I. We will measure the change in formation water saturations, determine the effectiveness of current waterflood operations, and identify any intervals that may require recompletion. We will report the findings from these surveys during the next few quarters.

\section{ACTIVITY II.3-INTEGRATION/VALIDATION}

\section{VALIDATION OF RESERVOIR CHARACTERIZATION - TASK II.3.1}

\section{Routine Core Analysis}

Routine core analysis has been performed on all newly acquired core. Porosity and permeability measurements have been made over the entire cored interval on all the 1 inch by 1 inch quick plugs, as well as on the 4 inch whole core across selected reservoir intervals.

\section{Thin Section Analyses}

Numerous thin sections of the cored intervals have been prepared. Plans are to use information from these thin sections to enhance our understanding of pore size, pore distribution, rock type, and depositional environment.

\section{Depositional Environments}

Additional refinements were made to the depositional environment model based on data from recently acquired core taken from the latest 10 -acre infill wells. The planned coring program and a cursory description of these cores have been completed. This represents $2,730 \mathrm{ft}$ of core in four wells. The preliminary depositional environments described from this new data are as follows:

\section{Qpen Shelf}

\author{
Open Shelf - general \\ Fusilinid Shoal \\ Shoal - general \\ Inter-Shoal \\ Reef \\ Reef Center \\ Reef Talus Apron
}


Reef Debris Apron

Open Lagoon

Restricted Lagoon

Island

Island Center

Near Island Beach

Algal Mat

Outer Island Beach

Tidal Flat

Algal Mat

Tidal Channel

Shallow Sub-Tidal Silty Dolostone

\section{Supratidal}

There are several significantly new features not noted from previous core descriptions. The first is the presence of large patch reefs and associated porous debris aprons in the Lower Clearfork within Section 327. Previous work suggested that a 'shelf' edge existed to the east of Section 327 , and that the large reefs would only exist along this shelf edge. This new core information implies that there is no shelf edge as such, just patch reefs and debris aprons scattered across the Unit. This information could help explain the erratic distribution of good producing wells in the south-central portion of the Unit. It is important to note that the debris aprons and shoals around these reefs typically have good reservoir quality. In addition, smaller and less well developed reefs and bioherms have been noted in the upper portions of the Middle Clearfork and Upper Clearfork.

The second new piece of information concerns the MF3 layer $( \pm 6,850 \mathrm{ft}$ ) of the Middle Clearfork that has been reinterpreted as a solution collapse breccia with associated open natural fractures. These features were caused by dissolution of carbonate beneath extensive exposure surfaces. The presence of these surfaces is supported by presence of coal beds, abundant 'fresh' water plant debris zones, erosion lag soils, and some root casts. Parts of the Unit were only partially exposed, most probably as a series of small islands and associated carbonate sand beaches. This information is of important economic significance, because there is more natural fracturing in the MF3 zone than previously thought. Further analyses will determine the interconnection and influence of this fracturing from solution collapse breccias. 


\section{Rock Fabrics}

We have described four basic rock fabrics:

1) Homogeneous--which is made up of relatively uniformly distributed lateral and vertical porosity and permeability. The best example of this type of rock fabric is found within selected portions of the MF1A layer. We are not implying that this zone is perfectly homogeneous like some silica clastic sands, however, this layer is much closer to this type of homogeneity than all other zones in the Clearfork.

2) Fractured--which is made up of solution collapse breccias as described above. Fractures are 2-4 inches in length and very roughly estimated to be 4-6 inches apart. Not all of these fractures are open, as many have been plugged with anhydrite. Portions of the MF3 layer are a good example of this fabric.

3) Bimodal--which is made up of two distinct pore sizes. The larger size pores are typically formed from the dissolution of fossil debris, and the smaller pores are typically intercrystalline in origin.

4) Heterogeneous--which is made up of anhydrite nodules, and porous dolostone. This fabric is common throughout much of the Clearfork/Glorieta section. The size and distribution of these anhydrite nodules vary dramatically.

\section{Mini-Permeameter Research}

This reservoir characterization tool has the ability to take multiple permeability and porosity measurements in a very small grid across the surface of slabbed core. One hundred and fifty feet of slabbed core from the NRU 3533 well has been analyzed by Core Labs for mini-permeameter and mini-acoustic porosity measurements. Early indications are that the miniperm permeabilities and porosities are reliable for most of the rock based on comparison to core plug analyses, whole core analyses, and thin sections.

Three vertical permeability traces, spaced 0.1 inches apart, were recorded. Vertical measurements of permeability along these traces were recorded every $0.1 \mathrm{inch}$. One vertical trace of acoustic measured porosity was recorded. This trace was positioned in the center of the core slab, and a measurement taken every $0.1 \mathrm{inch}$. It is hoped that this detailed information will give us a better understanding of small scale vertical and lateral permeability changes, help us to refine porosity versus permeability algorithms, improve our understanding of horizontal versus vertical permeability ratios, clarify our understanding of the effects of diagenesis on permeability, and provide additional data for reservoir flow simulation.

We plan to also send the slabbed core to the University of Tulsa for additional testing on their mini-permeameter machine. 


\section{Mud Logging}

We have captured continuous reading of all mud gas components while drilling, and loaded the data into a computer database and depth corrected it. In addition, we have started research into the applicability of using mud gas component ratios to estimate fluid content. It is hoped that flushed zones will have uniquely different ratios than previously uncontacted oil zones.

We have noticed also that the mud $\log$ is an excellent tool for locating the intervals that contribute most to production. In this particular shallow-shelf carbonate reservoir, it would appear that the pay intervals of interest could probably be cost-effectively defined simply by using the mud log and a base porosity and resistivity log. It is essential that a high quality and reliable mud logging company be chosen to do the work. Mud loggers with previous experience in the formation being drilled is also an important component in getting reliable data. If an operator requires more detailed information regarding porosity types, rock quality, and fluid distributions, then additional information must obviously be gathered.

\section{Open-Hole Logging}

The base logging suite for the 10-acre infill wells currently consists of a Dual Laterolog, Micro Laterolog or Micro-Spherically Focused Log ( $\mathrm{R}_{\mathrm{xo}}$ device), Compensated Neutron Log, Compensated Spectral or Litho-Density Log (includes PE), Spectral Gamma Ray Log, and a Sonic Log. We have utilized several potentially useful modern open-hole log tools in addition to our normal logging suite in an attempt to more accurately characterize permeability, fluid content, and rock fabric. Some of these are summarized below:

\section{High Frequency Dielectric Log}

The high frequency $(200 \mathrm{MHz})$ dielectric log yields a salinity-independent measure of fluid distributions in the flushed zone. This is of paramount importance in areas such as the North Robertson Unit that are currently under active waterfloods. The dielectric tool produces a much more accurate representation of pay intervals than can be obtained from the usual low frequency flushed zone resistivity devices, such as the MLL or MSFL, which do not always do a good job of differentiating between residual and movable hydrocarbons.

This device works extremely well in formations with mixed lithology, and if run in combination with a low frequency flushed zone resistivity device, yields a rock textural parameter that can be used to determine the type of porosity present (intergranular, vuggy, or fracture), which directly affects the producibility of any particular interval. 


\section{NMR Log}

Nuclear Magnetic Resonance (NMR) logs were recorded over selected sections of two cored wells in an effort to obtain permeability, lithology-independent porosity, pore size distribution, and fluid saturation distribution from a single log. Most of the preliminary NMR work has been performed to differentiate between oil and water in low-resistivity clastics, however, several recent projects performed in the Permian Basin area are adding to the understanding of NMR responses in high-resistivity carbonate reservoirs.

This device gave a reasonably good approximation of permeability, pore size, and the location of free hydrocarbons, however, data turnaround was slow, costly, and initially needs to be closely calibrated with core. The distribution of free and bound fluids in the rock pores obtained from NMR analysis of selected core samples from the two wells indicated that the reservoir is oil wet. This fluid distribution was then used in the processing of the raw log data to yield a visual representation of the pore and fluid distribution in the reservoir. Permeability is estimated using an empirical relationship involving the tool's porosity measurement and the $T_{2}$ time, or transverse relaxation time, required for a hydrogen molecule to re-orient itself after being 'tipped' by a magnetic pulse from the tool.

Given the fact that permeability and pore size change so rapidly in the Clearfork, the vertical resolution of the next generation of tools probably needs to be improved, and this is currently underway. Plans are to continue to evaluate the application of NMR technology for the Clearfork.

\section{Borehole Imaging Log}

We attempted to obtain log-based images of the borehole wall in two cored wells (NRU 1509 and NRU 3319) using both circumferential microresistivity imaging tools and acoustic-based imaging tools. The microresistivity imaging tool missed most of the small-scale features and many of the large scale features, most probably due to insufficient resistivity contrasts within the rock.

We were much more successful in identifying natural fractures, vugs, anhydrite nodules, and bedding planes using the acoustic imaging tool. We may attempt to record an additional acoustic-based image in one of the final two 10-acre infill wells to determine the degree of fracture propagation caused by long-term injection along the suspected east-west fracture trend.

\section{Porosity versus Permeability Relationships}

Improving our understanding of the relationship between porosity and permeability has been one of the key efforts of our geologic work. Our approach has been to integrate all geologic and engineering data in an attempt to refine our existing porosity-permeability algorithms, and 
to redefine flow unit boundaries. Now that we have finished the infill drilling program and loaded all new core and open-hole log data into our database, we can begin to update our porosity-permeability relationships and flow unit definitions as described in the following paragraphs.

Early indications are that by using multiple geologic 'filters' it is possible to dramatically reduce the scatter on our porosity versus permeability crossplots, thereby providing us with more robust algorithms. 'Filters' include devices such as depositional environment data, shallowing upward sequence tops, rock type data, mud log data, and numerous open-hole log responses (PE, Spectral Gamma-Ray, Invasion Profile, etc.).

Additionally, we have found that neural network technology allows us to combine curve data in multiple ways to help find unique permeability signatures. Our research has only just begun in this area, however, early results are very promising and we will continue to report our findings during Budget Period II.

Recently acquired mini-permeameter data may also prove useful in helping refine the porosity versus permeability algorithms. Early indications are that the miniperm permeabilities and porosities are reliable for most of the Clearfork and Glorieta rocks. We hope that this detailed information will give us a better understanding of small scale vertical and lateral permeability changes within varying rock types.

\section{Updating the Core-Log Model}

We have completed extensive work on improving the porosity versus permeability algorithms used in the early phases of this project. Results to date indicate that several new lines of research hold promise:

1) Generation of $\varnothing$ versus $k$ plots for each shallowing upward carbonate cycle (previously called flow unit tops).

2) Generation of $\varnothing$ versus $k$ plots for each depositional environment.

3) Use of Neural-Network programs to identify characteristic sequences based on core and $\log$ responses.

4) Improvement of the old core-log algorithms using new open-hole log data.

5) Formulation of unique $\emptyset$ versus $k$ relationships for small areas of the field related to the $\mathscr{\emptyset}$ versus $k$ relationships for the core in that area.

Fina geologists will work closely with David K. Davies \& Associates, Inc. in order to combine these various techniques and formulate the best method or combinations of methods to obtain optimal permeability-porosity relationships. 


\section{Special Core Analysis (SCAL)}

Approximately 120 preserved SCAL plugs were cut from the new whole core in 10-acre infill wells $1509,3533,1510$, and 3319 in order to obtain a representative sampling of all 'pay' rock types that were defined during Budget Period I. The SCAL plugs have been further screened using a computerized axial tomography (CT) scan machine at Texas A\&M University to eliminate the plugs that possess major barriers to flow (which is almost always in the form of anhydrite nodules).

A meeting was held on August 14, 1996, at the Fina Core Building to inspect CT images of 69 core plugs from NRU wells 1509 and 3533. The images were compared with the slabbed whole core and available thin-sections. From these 69 plugs, 26 were judged to be acceptable for future SCAL work. We are currently examining the results of CT scans for remaining core plugs from NRU wells 3533,1510 , and 3319. We will require approximately $45-50$ core plugs for our SCAL program. The remaining $20-30$ core plugs will be chosen in the near future, and we will ensure that we have a representative sampling of all reservoir rock types before proceeding.

The plugs will be sent to Core Petrophysics in Tulsa, Oklahoma during the next quarter for special core analysis. We will be performing wettability, relative permeability, capillary pressure, and electrical properties' measurements on the screened plugs to update our database for reservoir flow simulation. Results will be reported as they become available.

\section{VALIDATION OF RESERVOIR MANAGEMENT ACTIVITIES AND PERFORMANCE ANALYSIS - TASK II.3.2}

\section{Material Balance Decline Curve Analysis}

Once sufficient data are acquired, we will analyze early production data from new wells utilizing material balance decline type curve methodologies formulated during Budget Period I. Early rate and fluid level measurements will allow us to verify the results of previous analyses and obtain early estimates of individual well potentials, bottomhole pressures, and formation flow characteristics. The results of this work will be reported in the next Quarterly Progress Report.

\section{Formation Testing}

The formation test tool has provided individual layer pressures that can be used to better understand the way in which the productive interval depletes and repressures across the Unit. This can be used not only as a formation evaluation tool, but also as a reservoir conformance tool in an active waterflood. Using these results we can identify zones that are receiving insufficient or excess waterflood support. We may also be able to identify oil-water contacts on the basis of differing fluid gradients, although this will be difficult in what is now a fairly mature waterflood. 
Unfortunately, testing a low permeability, heterogeneous formation, such as the Clearfork, is extremely difficult. We utilized a low-force snorkel, a slow-drawdown choke with a very small pretest chamber $(5 \mathrm{cc}$ ), and a very soft packer pad (60 durometer) in order to have any chance at obtaining valid formation pressures. In addition, it is important to 'mud-up' prior to reaching total depth to ensure the presence of a stable mudcake prior to logging as all of these wells are drilled with brine water. Even taking the preceding precautions, we were only able to obtain valid pressures on about $15-20 \%$ of the tool sets. Data collected from three wells in the Section 327 infill area are shown in Fig. 3.

\section{Pressure Transient Tests}

Short-term pressure drawdown tests are being used to measure formation flow characteristics in the new producing wells. At this time, we prefer to record drawdown rather than buildup tests to avoid the shut-in of recently completed wells. These tests are being recorded over individual completion intervals (i.e., Lower, Middle, or Upper Clearfork), and are also being used to estimate the completion efficiency and the relative contribution of each zone to total production. This information will aid in injection well profile modification work to be performed during Budget Period II.

To date, we have recorded both Lower (NRU 3534) and Middle (NRU 3532) Clearfork drawdown tests in the Section 329 area, and Lower (NRU 1509) and Middle (NRU 2705) Clearfork drawdown tests in the Section 327 infill area. We have found that the hydraulic fracture jobs have been successful and are producing fractures with half-lengths on the order of $100 \mathrm{ft}$ (skin factor $=-5.0$ ). A log-log plot summarizing the results for the analysis of the NRU 3532 Middle Clearfork pressure drawdown test is shown in Fig. 4.

Results also indicate that the Middle Clearfork is a much more significant contributor to total production in both areas of the Unit than was previously thought. It also appears that the Upper Clearfork and Glorieta sections contribute very little to total production in both areas of the Unit, and this will be confirmed by future testing. At this point it appears that each interval's approximate contribution to total production is as follows:

\begin{tabular}{c|c|c|} 
& \multicolumn{1}{c}{ Section 327 } & Section 329 \\
\cline { 2 - 3 } Upper Clearfork & $5 \%$ & $10 \%$ \\
Middle Clearfork & $35 \%$ & $65 \%$ \\
Lower Clearfork & $60 \%$ & $25 \%$ \\
\hline
\end{tabular}

This information, together with newly acquired core and log data, has allowed us to target our completion intervals much more effectively.

We will perform additional pressure drawdown tests across selected completion intervals during the next quarter. In addition, we will perform extended pressure buildup tests on half of the new 
producing wells during Budget Period II as a part of the reservoir surveillance program. Pressure falloff tests will be recorded on all new injection wells after completion. Results will be reported as they become available.

\section{Injection Profiles}

The results of approximately 25 injection profiles recorded during the second quarter of 1996 indicate the need for a revised injection well workover plan. Many of the injectors contain large amounts of fill, and other wells inject into only a very small percentage of the total productive interval (usually the Lower Clearfork).

We will focus on improving injection efficiency in the new injectors by identifying the intervals in the producing wells that are the largest contributors to total production. Rather than attempting to inject water across a large $1200 \mathrm{ft}$ interval as was done previously, we will attempt to target fairly small, specific intervals. Profile modification may be attempted in existing injectors, and an effort will be made during the completion of new injection wells to avoid high permeability streaks that take most of the injection water. Results of some of this work will be available for the next Quarterly Progress Report.

\section{VALIDATION OF RESERVOIR SIMULATION - TASK II.3.3}

\section{Geostatistical Modeling}

During Budget Period II we will work on improving our geostatistical description methods to incorporate more information. We hope to integrate production profile and pressure transient data in future models. We also hope to define alternate ways of describing spatial continuity within the reservoir. User-friendly computer software will be developed for use by small and independent operators who are interested in utilizing these techniques.

The spreads in the oil rate forecasts from the different realizations completed during Budget Period I were too narrow, reflecting our inability to capture the degree of lateral discontinuity that is present in the Glorieta/Clearfork section. It would appear that the spatial distributions of the porosity and permeability were modeled with too much horizontal continuity, due to the estimated ranges of the corresponding variograms being too high. Some of these variogram ranges could not be determined directly from the data since they are shorter than the distances between wells.

More work is planned to improve the definition of the uncertainty in the reservoir model forecasts. New log and core data are being obtained from more closely spaced infill wells that will allow the spatial continuity of the porosity and permeability fields to be examined on a finer scale. Additional realizations of the reservoir model will be generated with less horizontal 
continuity, and then will be used to forecast reservoir performance as above. The effect of the horizontal continuity on the forecast spreads will then be observed.

\section{Deterministic Modeling}

All simulation models will be updated to incorporate changes in reservoir description (rock types), PVT, and special core properties as they become available during Budget Period II. We will also investigate the use of a dual-porosity simulation model to better capture the behavior of a reservoir consisting of high permeability productive streaks surrounded by large intervals of low permeability rocks that may act as a hydrocarbon source for those high-permeability intervals. If the number of reservoir layers in the simulation models can be significantly reduced, then several of the model areas may be combined into a larger simulation model to eliminate the current assumptions regarding boundary flux in each model area.

\section{ACTIVITY II.4-TECHNOLOGY TRANSFER}

\section{REPORT WRITING - TASK II.4.1}

The 1996 Annual Report was supplied to the DOE during the last quarter covering work performed from June 1995 to June 1996.

\section{NEWSLETTERS - TASK II.4.2}

The second Project Newsletter will be distributed during the first quarter of 1997.

\section{PUBLICATIONS AND PRESENTATIONS - TASK M.4.3}

No presentations or papers were completed during this quarter as the main emphasis of the project was on the Field Demonstration phase. Abstracts have been submitted for several professional meetings in 1997, and these presentations will be detailed in future Quarterly Progress Reports.

\section{TECHNOLOGY TRANSFER PACKAGES - TASK $I 1.4 .4$}

Technology transfer packages describing the results and methodologies used to date for this project were distributed at the two Technical Workshops completed during the last two quarters and will be made available to all interested parties on a continuous basis. The packages include the results of our analyses, and any software generated as a result of the work performed on this project. These packages will be updated during Budget Period II as more results become available. 


\section{TECHNICAL WORKSHOPS - TASK II.4.5}

The first two Technology Transfer Workshops were held in Midland, Texas on April 25-26, 1996 for approximately 60 industry personnel, and in Houston, Texas on June 13-14, 1996 for approximately 45 industry personnel. A written report, "Integrated Reservoir Management and Characterization to Optimize Field Development," containing the results of our current analyses, associated technical publications, and computer software generated as a result of the work performed on the project, was given to all attendees. The subject areas attracting major interest were geological reservoir characterization, reservoir performance analysis, and the comparisen of deterministic and geostatistical flow modeling. 


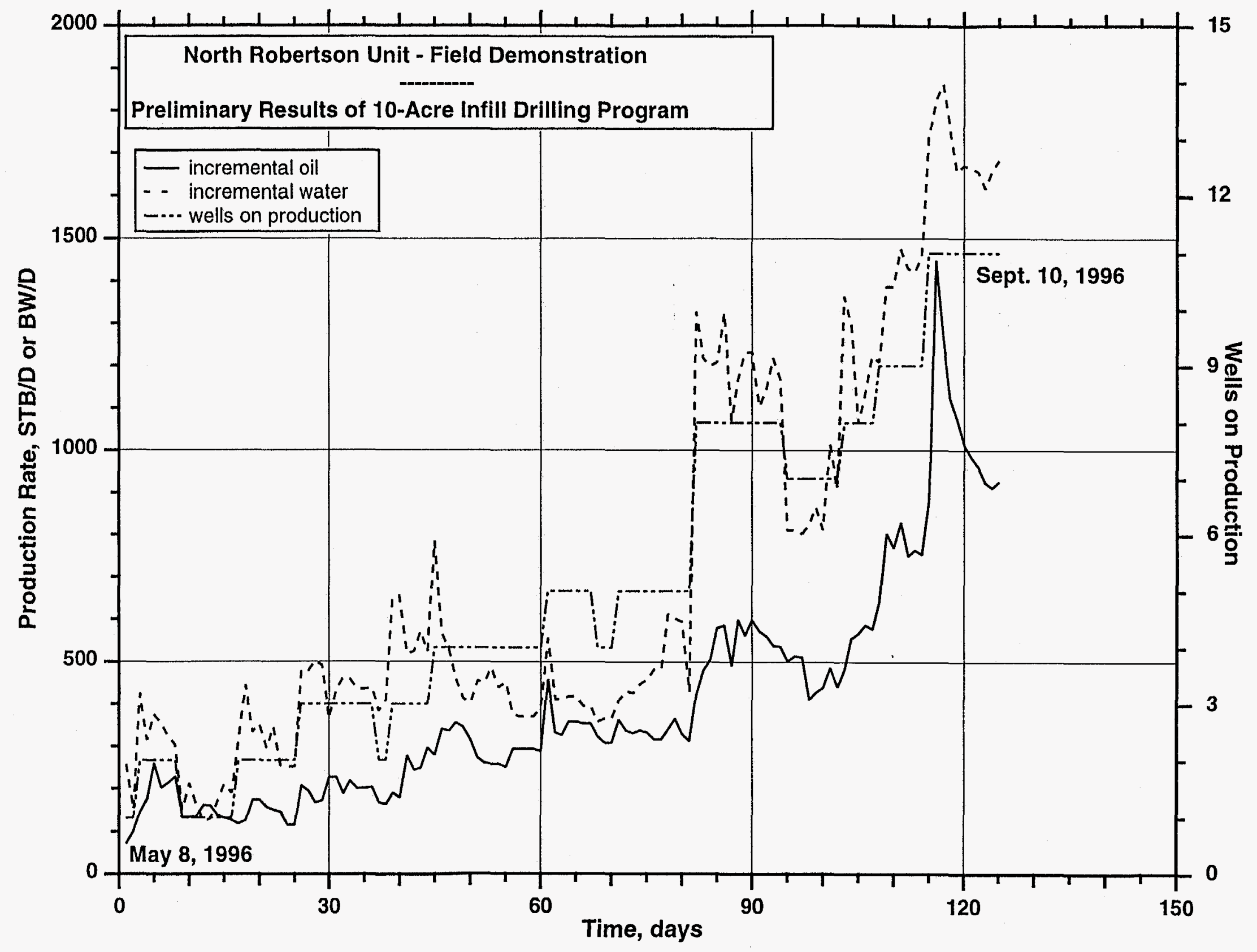

Figure 1 - Incremental Production Increase Due to New 10-Acre Infill Wells. 


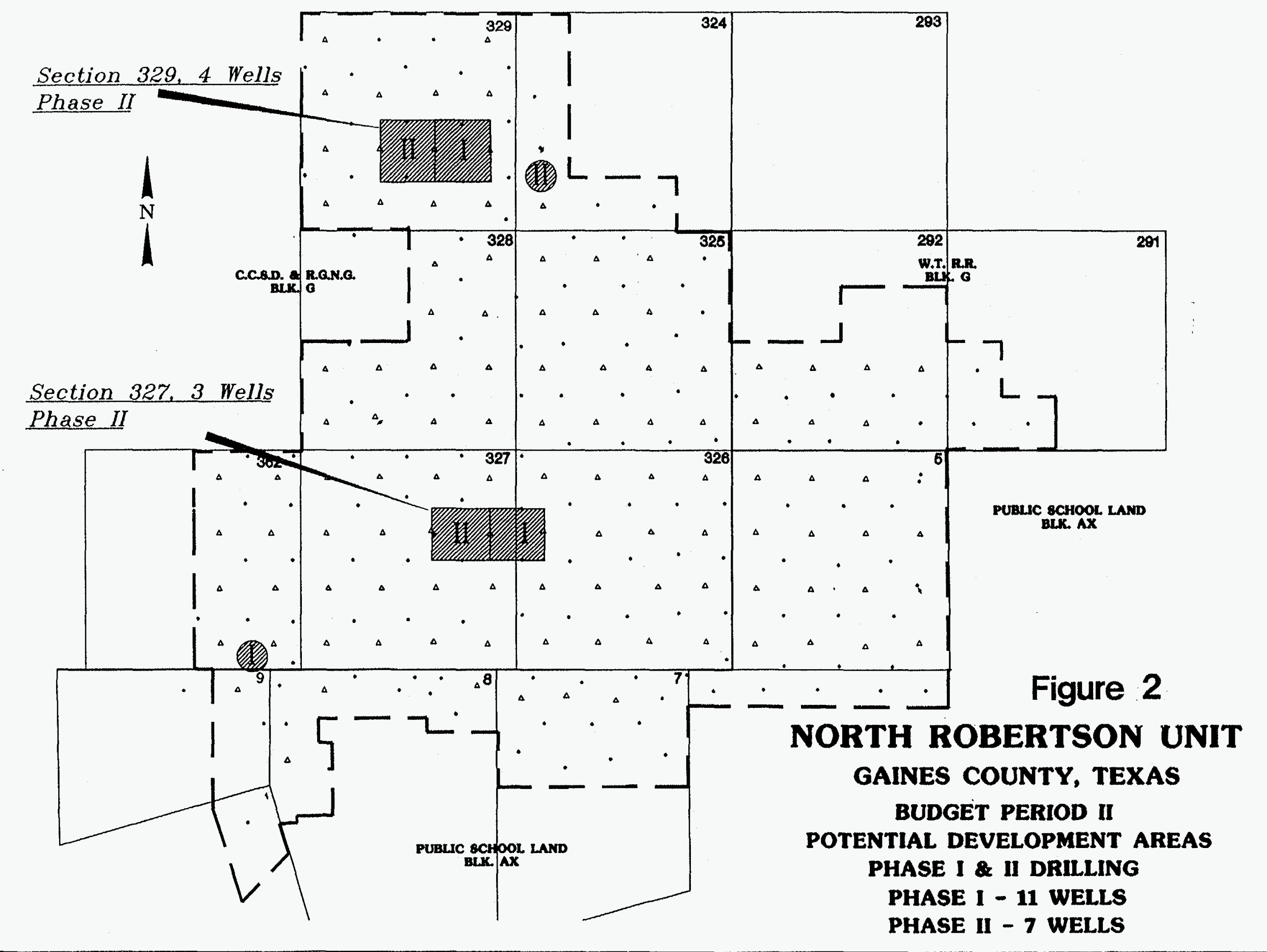




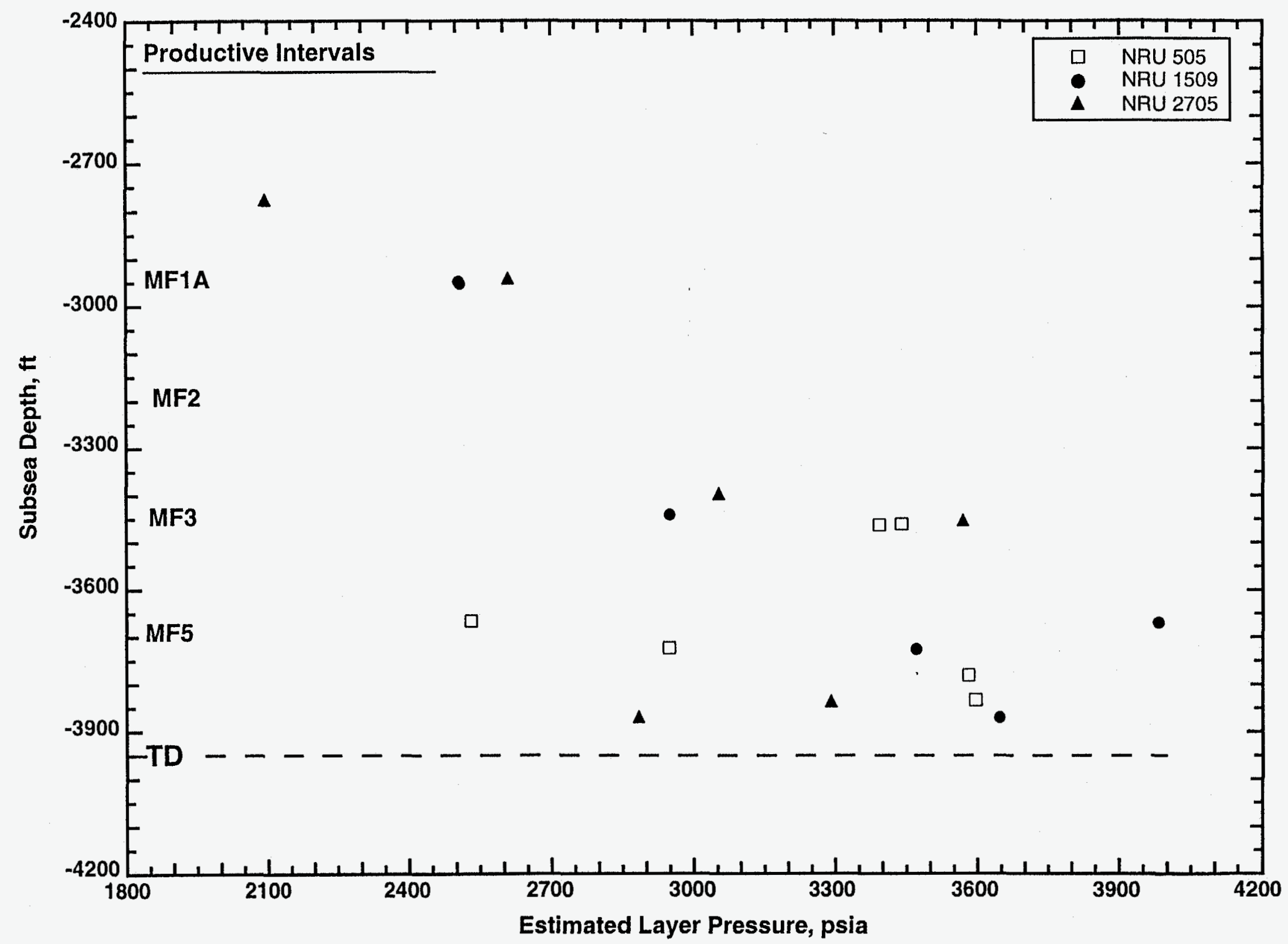

Figure 3 - Formation Test Layer Pressures from Three Wells in Section 327 10-Acre Infill Area. 


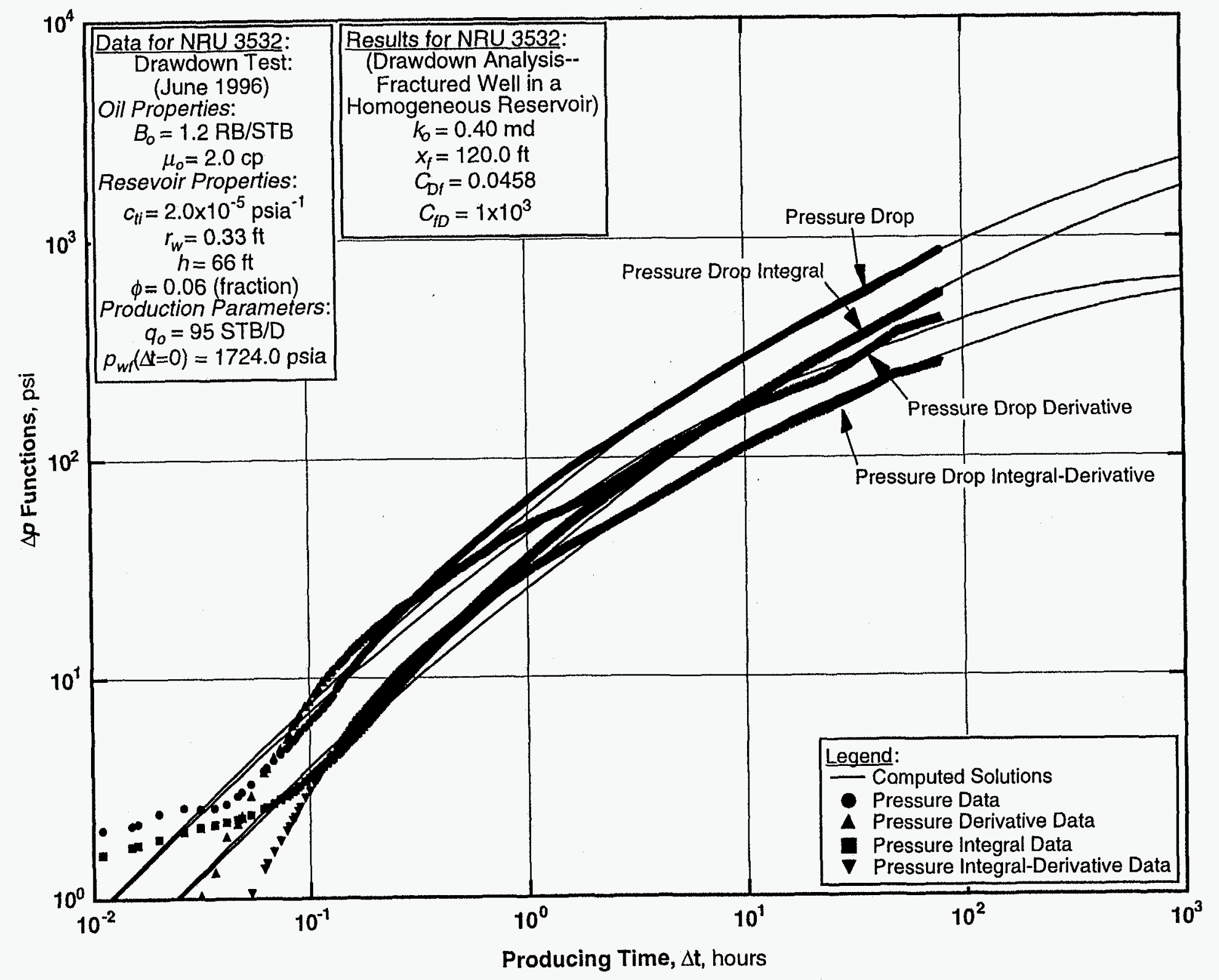

Figure 4 - Data Match on Log-Log Plot for Well NRU 3532 Pressure Drawdown Test (June 1996). Matched Using the Model for a Well with an Infinite Conductivity Vertical Fracture in an Infinite-Acting Homogeneous Reservoir. 